
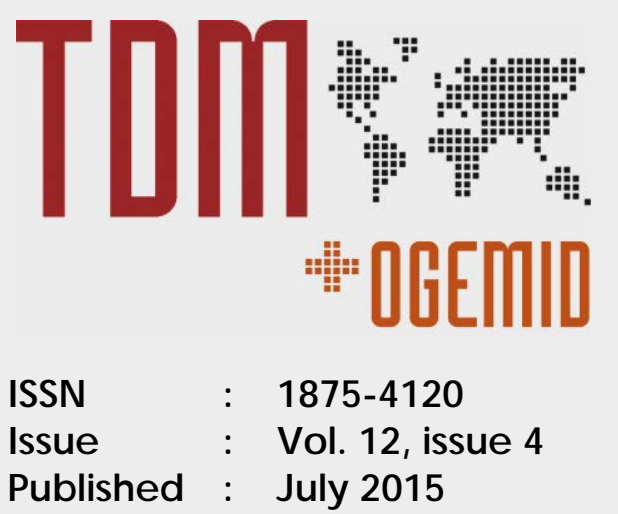

This paper is part of the TDM / ArbitralWomen special on "Dealing with Diversity in International Arbitration" edited by:
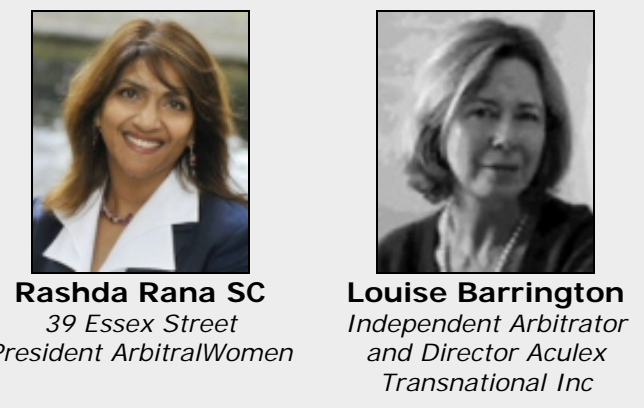

AREITRALWDMEN

The International Network of

Women in Dispute Resolution

Terms \& Conditions

Registered TDM users are authorised to download and print one copy of the articles in the TDM Website for personal, non-commercial use provided all printouts clearly include the name of the author and of TDM. The work so downloaded must not be modified. Copies downloaded must not be further circulated. Each individual wishing to download a copy must first register with the website.

All other use including copying, distribution, retransmission or modification of the information or materials contained herein without the express written consent of TDM is strictly prohibited. Should the user contravene these conditions TDM reserve the right to send a bill for the unauthorised use to the person or persons engaging in such unauthorised use. The bill will charge to the unauthorised user a sum which takes into account the copyright fee and administrative costs of identifying and pursuing the unauthorised user.

For more information about the Terms \& Conditions visit www.transnational-dispute-management.com

(C) Copyright TDM 2015 TDM Cover v4.1

\section{Transnational Dispute Management} www.transnational-dispute-managementcom

\author{
Diversity in Arbitration in Europe: Insights \\ From a Large Scale Empiric al Study \\ by A.N. Cole and P. Ortolani
}

\begin{abstract}
About TDM
TDM (Transnational Dispute Mana gement): Foc using on recent developments in the a rea of Investment a rbitration and Dispute Ma na gement, regulation, treaties, judic ial and arbitral c ases, voluntary guidelines, tax and contracting.
\end{abstract}

Visit www.transnational-dispute-mana gement.com for full Tems \& Conditions and subsc ription rates.

\section{Open to all to read and to contribute}

TDM has become the hub of a global professional and academic network. Therefore we invite all those with an interest in Investment arbitration and Dispute Management to contribute. We are looking ma inly for short comments on recent developments of broad interest. We would like where possible for such comments to be backed-up by provision of in-depth notes and articles (which we will be published in our 'knowledge bank') and primary legal and regulatory materials.

If you would like to partic ipate in this global network please contact us at info@transnational-dispute-management.com: we a re ready to publish relevant and quality contributions with name, photo, and brief biographic al description - but we will a lso accept anonymous ones where there is a good reason. We do not expect contributors to produce long academic articles (though we publish a select number of academic studies either as an advance version or an TDM-foc used republic ation), but rather concise comments from the author's professional 'workshop'.

TDM is linked to OGEMID, the principal intemet information \& disc ussion forum in the a rea of oil, gas, energy, mining, infrastructure and investment disputes founded by Professor Thomas Wälde. 


\title{
Diversity in Arbitration in Europe: Insights From a Large Scale Empirical Study
}

\author{
TONY COLE ${ }^{1}$ AND PIETRO ORTOLANI ${ }^{2}$
}

\begin{abstract}
Note: This is an in-process draft of an article that will be finalised later in 2015. It has been made available in this form through Transnational Dispute Management in order to facilitate the access of arbitration practitioners to the data it reports, as part of this Special Edition. However, it remains an early, rough draft. Consequently, all analysis, commentary and drafting remains in-process, and will be further developed in the final draft of the article.
\end{abstract}

\section{Introduction}

While issues of gender and ethnic diversity have become prominent in all areas of law, there is reason to believe that the insular nature of the arbitration community, combined with the importance of personal connections to receiving career opportunities in arbitration will make diversity a particularly complex matter in arbitration as a field of professional practice. That is, while there is no evidence that arbitration practitioners are as a group any more likely to discriminate on the basis of ethnicity or gender than other legal professionals, fields in which career progression is tightly linked to receiving the support of "gatekeepers" can present particular obstacles for non-Male and minority practitioners, who may be less likely to make strong social connections with those gatekeepers, and so be less likely to receive opportunities for career progression. ${ }^{3}$

In 2014 a team at Brunel University, as part of a study being conducted for the European Parliament, undertook a large-scale survey of arbitration practitioners across the European Union and Switzerland. ${ }^{4}$ While this Survey was not primarily focused on questions of diversity, all respondents were asked to self-identify both their gender ${ }^{5}$ and their ethnicity, ${ }^{6}$ with selection of

\footnotetext{
${ }^{1}$ Senior Lecturer, Brunel Law School; Director, Brunel Centre for the Study of Arbitration and Cross-Border Investment.

${ }^{2}$ Senior Research Fellow, Max Planck Institute Luxembourg for International, European and Regulatory Procedural Law, Comparative Procedural Law.

${ }^{3}$ See, e.g. http://www.legalservicesboard.org.uk/what_we_do/Research/publications/pdf/literature_review_on_diversity2.pdf at 13 .

4 Tony Cole, Ilias Bantekas, Federico Ferretti, Christine Riefa, Barbara Warwas and Pietro Ortolani, 'Legal Instruments and Practice of Arbitration in the EU' (EU Parliament Study for the JURI Committee) <http://www.europarl.europa.eu/RegData/etudes/STUD/2015/509988/IPOL_STU\%282015\%29509988_EN.pdf> accessed 21 May 2015.

5 The available options were: "Male”, "Female” and "Other”.
} 
multiple ethnicities being permitted. Consequently, although the Survey aimed at offering a comprehensive picture of arbitration in all EU Member States and Switzerland, rather than focusing on the specific question of diversity, it generated information on both the levels of nonMale and ethnic minority involvement in arbitration, and, through cross-analysis of data, on career progression within arbitration of non-Male and ethnic minority arbitration practitioners. This article will provide a brief overview of these results, which do indeed indicate ongoing diversity-related problems within arbitration.

\section{Methodology of the Survey}

As already mentioned, the results reported in this article were generated through the use of a large-scale Survey that was delivered in all States of the European Union and Switzerland. Particular attention was paid to the methods used for generating participants in the Survey, as the reality of arbitration as a field of practice means that it is not possible to identify a discrete group of individuals engaged in arbitral practice, and ask them to complete a survey. Rather, while in each jurisdiction covered by the Survey there were identifiable leading arbitration practitioners, a large amount of arbitration work is often done by individuals who do not specialize in arbitration, but rather specialize in another field and practice arbitration on a more occasional basis. In order to generate a realistic picture of arbitral practice, however, rather than merely to repeat the traditional focus of academic arbitration study on leading arbitral practitioners, it was necessary to include such non-specialist practitioners amongst those answering the Survey.

That is, the reality that arbitration as a field of practice is routinely divided into a smaller "core" of leading specialists and a larger "periphery" of less specialized individuals means that a survey solely of individuals in the "core" would risk generating results reflecting solely how arbitration was practiced by its most specialised practitioners, thereby misrepresenting a practical reality in which much arbitration work is done by individuals for whom arbitration is not their central area of work. On the other hand, as the "periphery" is substantially larger than the "core", a broad survey open to all respondents would risk generating results overwhelmed by responses from individuals who engage in arbitration relatively rarely, thereby misrepresenting again the reality of arbitral practice.

This problem was addressed by promoting the Survey in two broad ways. Firstly, international directories were used to identify individuals who could plausibly be seen as members of the "core" of arbitration practitioners within each State, and these individuals were directly contacted and invited to take the Survey. Two of these directories, Chambers Europe and WhosWhoLegal, are best understood as focusing on the "elite" level of practitioner, and individuals recommended in these guides for their arbitration expertise were invited to take the

\footnotetext{
${ }^{6}$ The available options were: “American Indian or Alaska Native”, “Asian”, “Black or African American”, “Native Hawaiian or Other Pacific Islander”, "White”, “Arab and Middle Eastern”.
} 
Survey. The third guide, Legal500, provides a broader coverage of domestic legal practice, and was therefore important as a means of identifying individuals with strong domestic practices but potentially less international recognition. In order to achieve this goal, Legal500 was used differently, and individuals were invited to take the Survey if they were identified by Legal500 as prominent in litigation within a State and they self-identified as an arbitration practitioner on their law firm website.

The second method of generating participants in the Survey, designed to encourage the participation of "periphery" members of arbitral practice in each State, involved opening the Survey to public participation, by any individual who engaged in the practice of arbitration, whether as a lawyer or as an arbitrator. In order to achieve this goal, the Survey was promoted in a number of ways: (i) the leading arbitral institutions in each State were contacted and asked to promote the Survey; (ii) the Chartered Institute of Arbitrators, the leading global professional arbitration institution, distributed the survey to its membership; (iii) links to the survey were distributed several times on OGEMID, the central online discussion forum for arbitration specialists; (iv) two postings were made on the Kluwer Arbitration Blog, a widely read specialised arbitration blog; (v) law firms identified in Chambers Europe as leading litigation firms in each State covered by the Survey were contacted, and asked to distribute the survey to any individuals at their firm engaged in arbitration; (vi) law societies and similar professional bodies were contacted and asked to distribute the survey. Furthermore, in order to ensure maximum participation, the Survey was translated into all official languages of the European Union.

The Survey was ultimately taken by 871 respondents across all States in the European Union/Switzerland, with 723 respondents (83\%) completing all questions asked. Because of the cross-border nature of much arbitration practice, individuals were asked to identify the State in which they primarily worked, rather than being allocated to a particular State based upon their geographical location. Distribution of respondents across the European Union was high, with individuals from England, Wales and Northern Ireland, the source of the largest number of respondents, constituting only $19.29 \%$ of the whole, and all States providing at least 8 respondents. $^{7}$

\footnotetext{
${ }^{7}$ While the number of respondents from England, Wales and Northern Ireland is significantly larger than the next largest source of respondents, France (6.08\%), it is unclear that this constitutes the result of any English-language bias. Such a bias certainly cannot be discounted as potentially part of the explanation, however London has become the leading centre for arbitration practice in Europe, and has by far the largest concentration of leading arbitration professionals of any city in Europe. Consequently, while the most accurate ratio of English arbitration respondents to non-English respondents is obviously open to question, it is to be expected that significantly more respondents would report England, Wales and Northern Ireland as their State than any other State.
} 


\section{Gender Imbalance}

\subsection{Distribution of Respondents}

An initial indication of an ongoing gender imbalance in European arbitration can be seen in the make-up of respondents to the Survey, as of 871 respondents, 701 described their gender as "Male” (80.48\%), whilst 169 answered "Female" (19.40\%) and 1 (0.11\%) answered “Other". These results cannot, of course, be claimed to present a reliable picture of the field of arbitration as a whole, as participation in the Survey was purely voluntary. However, given the large number of participants, and the efforts described above to promote the Survey and to encourage participation, the extent of the gender imbalance amongst Survey respondents provides substantial justification for concluding that a similar imbalance exists within the profession as a whole.

Importantly, the male/female ratio in the population of Survey respondents varies greatly from one State to another, although in only a single State, Latvia, were there more non-Male respondents than Male. Moreover, in only two other States, Malta and Romania, were over 40\% of respondents non-Male. Notably, there is also no justification for any belief that gender imbalance within arbitration results solely from gender imbalance in the larger legal community, as might be indicated, for example, if States with larger and more developed arbitration communities displayed higher levels of gender equality within arbitration practitioners. There is, however, no evidence that having a larger and more developed arbitration community has any impact on the levels of gender imbalance within the field. Indeed, of the four leading arbitral jurisdictions (England, France, Sweden, Switzerland), only France had a greater than average proportion of female respondents (30.19\%), with each of the remaining three having a lower than average proportion (England: 13.69\%, Sweden: 18.37\%, Switzerland: 16.33\%). Whatever the primary source of the observed gender imbalance, then, there is no indication that having a welldeveloped arbitral community has an impact on remediating that effect.

Although the demographics of survey respondents cannot be invoked to draw bright-line conclusions on the social realities of the arbitration industry throughout Europe, empirical evidence emerging from the Survey strongly indicates that gender imbalance in arbitration is currently a problem, affecting to varying degrees most of the Continent.

\subsection{Gender and Career Progression in Arbitration}

While the imbalances just discussed in the numbers of Survey respondents provides an initial indication that significant gender imbalances exist within arbitration, they don't provide any suggestion as to the cause of these imbalances. As just noted, there is no evidence that having a highly developed arbitration community will reduce gender imbalances, but it could nonetheless be that the gender imbalance observable in arbitration in Europe is entirely 
attributable to broader social and professional factors, rather than to anything attributable to arbitration itself. Other results from the Survey, however, provide strong evidence that there are indeed features of arbitration as a field of practice that can be seen as contributing significantly to the gender imbalance observable within the field.

For example, Male and non-Male Survey respondents provided notably different responses when asked to describe the roles they currently play in arbitration. Whereas $66.76 \%$ of Male respondents reported serving as Lead Counsel in at least some of the arbitrations in which they have been involved in the past 5 years, this was true for only $57.06 \%$ of non-Male respondents. In a parallel result, while only $24.96 \%$ of Male respondents reported having served as counsel "assisting the lead counsel" in an arbitration within the past 5 years, this response was given by $36.47 \%$ of female respondents.

Notably, however, while this result provides initial evidence for the existence of obstacles to career progression for non-Male arbitration practitioners, further results provide a more complex picture. For example, non-Male respondents were more likely to report having been involved in arbitration from at or near the beginning of their legal careers than were Male respondents. Similarly, non-Male respondents were less likely to report that arbitration was not their primary field of practice than were Male respondents, and amongst those respondents for whom arbitration was their primary field of practice, non-Male respondents reported it becoming their primary field of practice at an earlier point in their careers than did Male respondents. Similarly, non-Male respondents on average reported arbitration constituting a higher proportion of their total workload over the past 5 years than did Male respondents.

The picture created by these results, that is, is not of a field in which internal obstacles simply prevent career development for non-Male respondents, but rather one in which opportunities are available but concentrated. That is, the low proportion of non-Male arbitration practitioners indicates that there are obstacles to entry to the field for non-Male practitioners, however the results just discussed suggest that those given entry often receive significant opportunities for career advancement. The situation this suggests, then, is one in which recognition within the field of the reality of gender disparity has led to active attempts to develop the careers of non-Male arbitration practitioners, however this has been done by focusing career development efforts on specific, identified non-Male individuals, rather than through efforts to remove career barriers more broadly. In short, non-Male practitioners who gain a solid place within the field appear to benefit from attempts to support the career development of non-Male practitioners - however attaining that initial solid place within the field remains a significant difficulty. Further support for this reading of these results can arguably be found in the fact that non-Male respondents were more likely to report involvement in the elite practice of investment arbitration than were Male respondents. 


\subsection{Gender and Working as an Arbitrator}

While the preceding results indicate that efforts are being made within arbitration to provide opportunities to non-Male arbitration practitioners, a more difficult situation appears when Survey results are considered regarding working as an arbitrator.

Survey respondents were asked whether they have served as an arbitrator in the past five years. The answer 'no' was given by $45.07 \%$ of non-Male respondents; for the sake of comparison, the same answer was given by only $31.19 \%$ of Male respondents. Given the disparity between the number of Male and non-Male respondents to the Survey, this entailed that non-Male practitioners constituted only $16.12 \%$ of all respondents to the Survey who had served as an arbitrator in the past five years, compared with the $19.51 \%$ of all Survey-respondents who were non-Male. This result offers a first, superficial indication as to the advantage that Male respondents enjoy in developing careers as arbitrators, the highest-status position within the field.

This result might initially seem at odds with the preceding results, which suggested that career opportunities were being provided to non-Male practitioners, even though the field itself remained gender imbalanced. In such a situation it might be expected that the proportion of nonMale practitioners serving as arbitrators should actually be higher than the proportion of nonMale practitioners within arbitration as a field of practice, as they will be on average more likely to receive the "career progression" opportunity of serving as an arbitrator. Further results from the Survey indicate, however, that despite the apparent conscious efforts within arbitration as a field of professional practice to promote the career development of non-Male practitioners, significant obstacles exist to access by non-Male practitioners to the role of arbitrator, and to career progression as an arbitrator.

For example, in line with the fact that, as noted above, non-Male respondents on average reported becoming involved in arbitration at an earlier stage of their career than did Male respondents, and reported arbitration both constituting a larger proportion of their work and becoming their primary specialism earlier in their career than was the case for Male respondents, non-Male respondents also reported receiving their first appointment as arbitrator earlier than did Male respondents. Importantly, however, how this fact must be qualified in important ways: $13.58 \%$ of Male respondents ${ }^{8}$ received their first appointment as an arbitrator within the first five years of professional activity; by contrast, only $8.97 \%$ of non-Male respondents gave the same answer. However, while $57.69 \%$ of non-Male respondents received their first appointment as arbitrator within 10 years of entering their profession, only $45.18 \%$ of Male respondents gave the same answer. Consistent with this latter result, while $21.48 \%$ of Male respondents waited more than 15 years before their first appointment as arbitrator, this was true of only $41.10 \%$ of non-

\footnotetext{
${ }^{8}$ In this context, the expressions 'male respondents' and 'non-male respondents' obviously encompass only those respondents who have received at least one appointment as arbitrator in the past five years.
} 
Male respondents. In other words, the results concerning Male respondents are more polarised, with Male respondents being more likely than non-Male respondents to receive their first appointment within 5 years of entering their profession, ${ }^{9}$ but being likely to have to wait longer for their first appointment if it has not been received in that early phase.

This result is consistent with the situation that has been described above, in which access to career progression opportunities is controlled by gatekeepers who select individuals to receive these opportunities. The early advantage of Male respondents can arguably be attributed to the enhanced ability such individuals will have at making social connections in a Male-dominated profession, thereby generating early career opportunities, while the earlier appointments for nonMale respondents outside this initial period arguably reflect recognition within the field of the low proportion of non-Male arbitrators, and active efforts to provide opportunities for non-Male practitioners to become arbitrators.

Supporting evidence for this interpretation can be found when examining how those individuals who received an appointment as an arbitrators within 5 years of entering their profession received that appointments. Male respondents show a diversity of sources of appointments, with 54.55\% receiving their first appointment from an arbitral institution, 12.73\% receiving an appointment as chair by a party or party-nominated arbitrators, $5.45 \%$ receiving an appointment derived from a social connection with a representative of the appointing party, 9.09\% receiving an appointment from a party for whom they had previously performed work, $14.55 \%$ from a party with which they had no previous connection, and one respondent receiving an appointment from a court. In stark contrast to this diversity, all but one non-Male respondent who received an appointment as arbitrator within five years of commencing professional work received that appointment from an arbitral institution; the sole exception receiving the appointment from a party for whom they had previously performed work. On the other hand, if non-Male respondents who received their first appointment as arbitrator within 5-10 years are considered, the same diversity of sources of appointment appears that is found for Male respondents in the $0-5$ year period.

In addition, there is also evidence that differences exist between the experiences of nonMale and Male arbitrators even once a first appointment has been obtained. Both categories of arbitrator respondents report spending equivalent amounts of time working as arbitrator, which might indicate that once a first appointment has been received, there are no significant barriers to non-Male arbitrators securing arbitrator work. However, evidence from the Survey suggests that differences remain both in how appointments are secured, and in the type of appointments that are secured.

For example, $46.15 \%$ of non-Male arbitrator respondents reported that over $50 \%$ of their appointments as arbitrator over the past 5 years were received from an arbitral institution, with

\footnotetext{
${ }^{9}$ Whether law or some other profession.
} 
32.05\% reporting over 75\%. By contrast, only 32.10\% of Male arbitrator respondents reported that over $50 \%$ of their appointments as arbitrator over the past 5 years were received from an arbitral institution, with only $16.54 \%$ reporting over $75 \%$.

Conversely, private parties appear to be less likely to appoint a non-male arbitrator, with $38.46 \%$ of non-Male respondents not having been appointed in the past 5 years by a party with which they had no previous contact, while only 25.93\% of Male respondents gave the same answer. Moreover, non-Male respondents are less likely to benefit from repeat appointments, $71.79 \%$ of non-Male arbitrator respondents not having been appointed in the past 5 years by a party that had previously appointed them as arbitrator, compared with $61.73 \%$ of Male arbitrators. Similarly, while $79.49 \%$ of non-Male arbitrator respondents had not been appointed by a party that had previously participated in an arbitration in which they had been appointed by the opposing party, this was true of only 59.75\% of Male arbitrator respondents.

In addition, Male arbitrators appear to receive a benefit in terms of repeat appointments through other arbitration practitioners. 50.62\% of Male arbitrator respondents reported receiving at least one appointment in the past 5 years from a party whose counsel had previously represented a party that had appointed them as arbitrator, with $13.08 \%$ reporting that such appointments constituted over $25 \%$ of their appointments in this period. By contrast, only $34.62 \%$ of non-Male arbitrator respondents reported having received such an appointment, with only $8.97 \%$ reporting that such appointments constituted over $25 \%$ of their appointments in this period.

These results suggest, then, that while non-Male arbitrators are able to generate as much work as Male arbitrators, they do so through different mechanisms, relying in particular on appointments from arbitral institutions, many of whom have adopted express policies of appointing non-Male arbitrators, as a means of providing career development opportunities. This interpretation receives further support from the fact that when asked which factors are most important in selecting an arbitrator, non-Male arbitrators are more likely than Male arbitrators to emphasise objective factors such as examination of publications and prior awards by an arbitrator, or the arbitrator's expertise in the subject matter of the dispute, and less likely than Male arbitrators to emphasise connections-based factors such as a party's personal knowledge of an arbitrator or that the arbitrator has been personally recommended to the party. Non-Male arbitrators, that is, appear to be less able to benefit from the social connections that play such an important role in arbitration as a field of practice, and must instead generate appointments through objective demonstrations of expertise.

It is, however, not merely the source of appointments that appears to differ notably between Male and non-Male arbitrators, as there is also evidence that non-Male arbitrators may on average receive less prestigious appointments. The "prestige" of an appointment is, of course, extremely difficult to measure, however one factor that can be considered is where arbitrators have been appointed. That is, regular appointments in States that are major arbitral 
centres provide strong evidence that an arbitrator is receiving prestigious appointments, while a history of appointments dominated by appointments in more peripheral arbitral jurisdictions would suggest that the individual in question has not yet successfully entered the core of the profession. When this data is examined, however, significant differences can be seen between the types of appointments received by Male and non-Male respondents. For example, while $16.12 \%$ of all Survey respondents who have served as an arbitrator in the past 5 years were nonMale, only $12.85 \%$ of respondents who have served as arbitrator in an arbitration seated in England in the past 5 years were non-Male, only 13.17\% for France, 13.13\% for Sweden, and $10.71 \%$ for Switzerland. That is, the results of the Survey indicate that non-Male practitioners are less likely to serve as arbitrators in the four major arbitral jurisdictions in Europe than are Male arbitrators.

This being said, however, two further results must be taken into account, which complicate this picture somewhat. Firstly, as the preceding results would suggest, Male respondents were far more likely than non-Male respondents to report having received an appointment as arbitrator in the past 5 years that was seated in a State outside Europe, with $22.47 \%$ of Male respondents having received such an appointment, compared with only $12.82 \%$ of non-Male respondents. Nonetheless, non-Male arbitrator respondents who reported having received appointments outside Europe in the past 5 years reported appointments throughout the world, rather than merely in countries bordering upon Europe. This provides an initial indication that while the practices of most non-Male arbitrators are on average more peripheral than those of Male arbitrators, certain non-Male arbitrators have nonetheless achieved elite levels of practice, developing reputations that enable them to operate a truly global practice.

Further support for such a conclusion can be seen when considering the percentage of appointments arbitrator respondents received in proceedings seated in States other than their home State. Such appointments not only indicate that an arbitrator has a transnational reputation, but arbitrators acting in foreign jurisdictions are also more likely to deal with complex transnational disputes, generally reserved to the elite of the profession. The answers of non-Male respondents are much more polarised than those of Male respondents: a higher proportion of non-Male respondents stated that either none $(47.44 \%)$ or $76-100 \%(14.10 \%)$ of their appointments as arbitrators concern proceedings seated in a jurisdiction other than the State where they mainly operate, whilst the same answers were given by respectively $37.28 \%$ and $7.90 \%$ of Male respondents.

What these results indicate is that that non-Male arbitrator respondents may be divided into two broad groups: on the one hand, an élite of non-Male arbitrator respondents ${ }^{10}$ practice at a truly international level, focusing on transnational arbitrations commonly seated in jurisdictions other than their home State. At the opposite end of the spectrum, a significant number of non-

${ }^{10}$ Represented in the survey results by $14.10 \%$ of them, whose appointments entirely or almost entirely relate to foreign-seated arbitrations. 
Male arbitrator respondents have more limited practices, often restricted to their Home State. The main difference between Male and non-Male arbitrator respondents is that the Male population is characterised by a richer range of in-between scenarios, with a higher proportion of Male arbitrators acting partially in their home State and partially in foreign seats. Conversely, the non-Male population seems to be more drastically divided into two different classes: one smaller group operating internationally, and one larger group for which arbitrator activity is exclusively limited to one jurisdiction. In light of this, it can be concluded that there are a number of nonmale arbitrators whose work has a distinctive international dimension and presumably focuses on complex transnational cases; however, the polarization of the results seems to suggest that the current gender imbalance within the field makes it difficult for most non-Male arbitration practitioners to achieve any 'in-between' result, combining a domestic professional arbitration practice with a moderate proportion of international appointments.

\section{Ethnicity-Based Imbalance}

The Survey results evidence a dramatic lack of ethnic diversity in the arbitration field throughout the whole continent: only 30 of 871 Survey respondents described their ethnicity as other than "White", including those who also self-identified as "White". ${ }^{11}$ Survey-wide, this means that $97.93 \%$ of practitioner respondents self-described as White, including respondents who selected both White and another ethnicity, with $96.56 \%$ of respondents selecting only White. Amongst those respondents self-identifying as non-White, 50.00\% self-identified as “Arab and Middle Eastern”12, 33.33\% as “Asian”, ${ }^{13} 13.33 \%$ as "Black or African American”, ${ }^{14}$ and $10.00 \%$ as "American Indian or Alaska Native". ${ }^{15}$

Notably, these results change little if only the four leading arbitral jurisdictions (England, France, Sweden, Switzerland) are considered, with $95.05 \%$ of respondents self-identifying as wholly or partially White. Lack of ethnic diversity, that is, is a characteristic of arbitration as a field of practice across Europe, even in those jurisdictions most likely to attract foreign practitioners, and in which arbitration practices are most likely to have non-European clients, from States that are themselves predominantly non-White. Moreover, amongst those respondents who reported that international commercial arbitration constituted over $50 \%$ of their

\footnotetext{
11 Notably, 33.33\% of respondents who described their ethnicity as something other than 'White' qualified their gender as 'Female' or 'Other', while only $19.51 \%$ of respondents who described their ethnicity as 'White' qualified their gender as either 'Female' or 'Other'.

12 “A person having origins in any of the original peoples of the Middle East or North Africa”.

13 “A person having origins in any of the original peoples of the Far East, Southeast Asia, or the Indian subcontinent including, for example, Cambodia, China, India, Japan, Korea, Malaysia, Pakistan, the Philippine Islands, Thailand, and Vietnam”.

14 “A person having origins in any of the Black racial groups of Africa - includes Caribbean Islanders and other of African origin”.

15 “A person having origins in any of the original peoples of North and South America (including Central America), and who maintains a tribal affiliation or community attachment”.
} 
arbitration work (a field in which ethnic diversity would arguably be a virtue), $97.28 \%$ of such respondents described themselves as wholly or partially White. Arbitration as a field of practice in Europe, that is, retains its ethnic homogeneity even in contexts in which ethnic diversity would appear to provide benefits.

The small number of Survey respondents self-identifying as non-White makes it difficult to run complex sub-analyses aimed at understanding the impact of ethnicity on career progression in the arbitration industry. However, some initial observations can be made. For example, $72.41 \%$ of respondents who did not describe their ethnicity as "White" were involved in their first arbitration within the first 2 years of professional activity, compared with $44.67 \%$ of respondents Survey-wide. However, no non-White respondent received their first appointment as arbitrator within the first 5 years of professional practice, compared with $12.84 \%$ of respondents Survey-wide.

The contrast between these results can arguably be explained by the same obstacles to the development of social connections within the field as are encountered by non-Male respondents, who similarly had lower levels of early arbitrator appointments than Male respondents. However, while non-Male respondents were able to rely upon active efforts by arbitral institutions to provide non-Male arbitrators with early appointments, none of the institutions interviewed during the course of the Study of which this Survey was a part identified ethnicity as an important consideration in appointing arbitrators.

What these results suggest, that is, is that while non-White and non-Male arbitration practitioners share similar obstacles in terms of benefiting from the social connections that facilitate career progression in arbitration, non-White practitioners face an additional obstacle in that while gender imbalance in arbitration has been identified as a problem that must be addressed, ethnic imbalance has not.

\section{Conclusions}

While the results reported here constitute only an initial analysis, and a more complex analysis will be produced in the finalized version of this article, the data itself makes clear that significant problems remain within arbitration with respect to both gender and ethnic diversity. Moreover, while efforts are being made to address gender diversity, and some impact of these efforts can be seen, even these efforts appear to be counteracted by aspects of arbitration as a field of professional practice, in particular the importance of social connections for professional development and career opportunities. 


\section{Graphical Appendix}

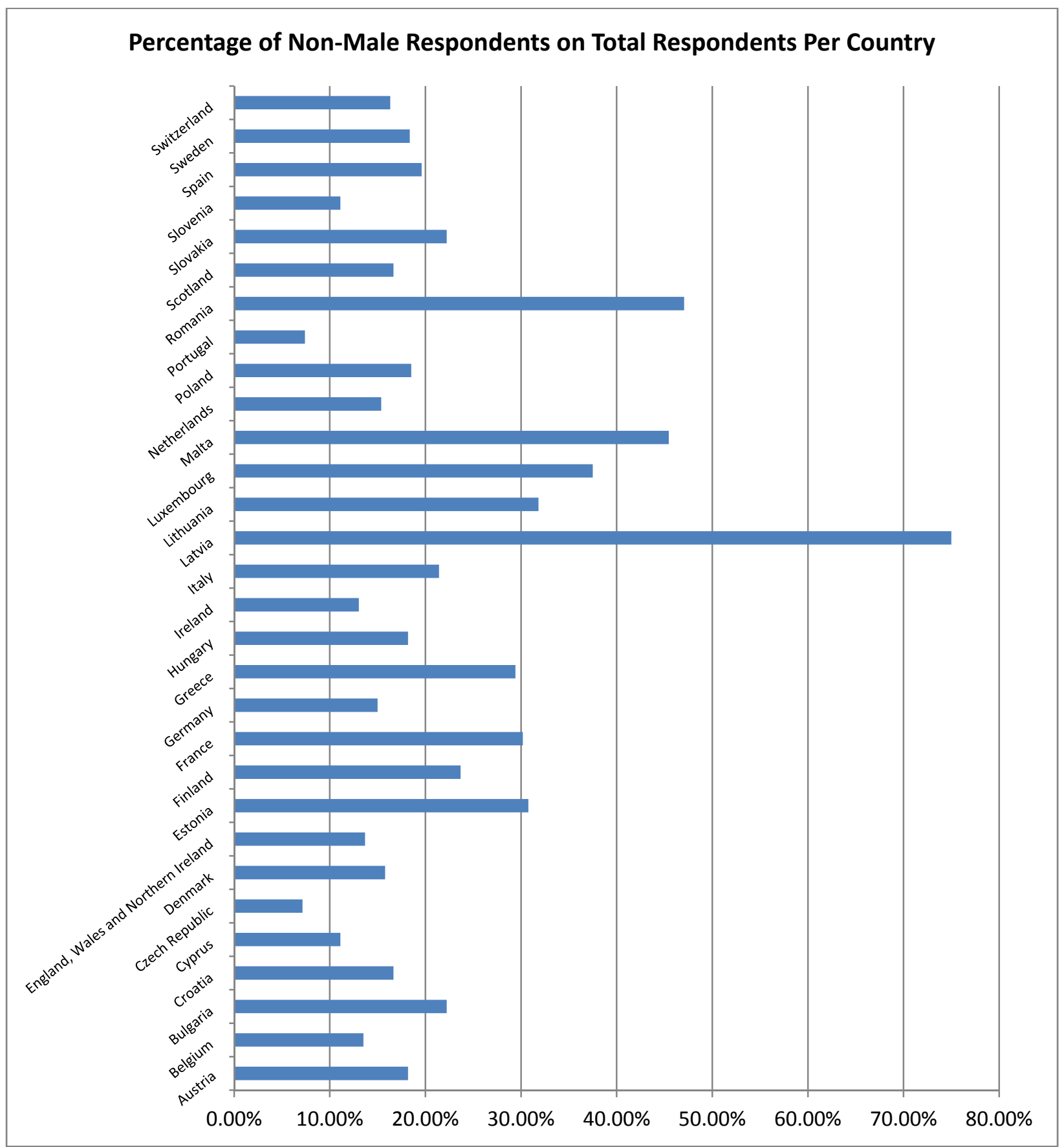




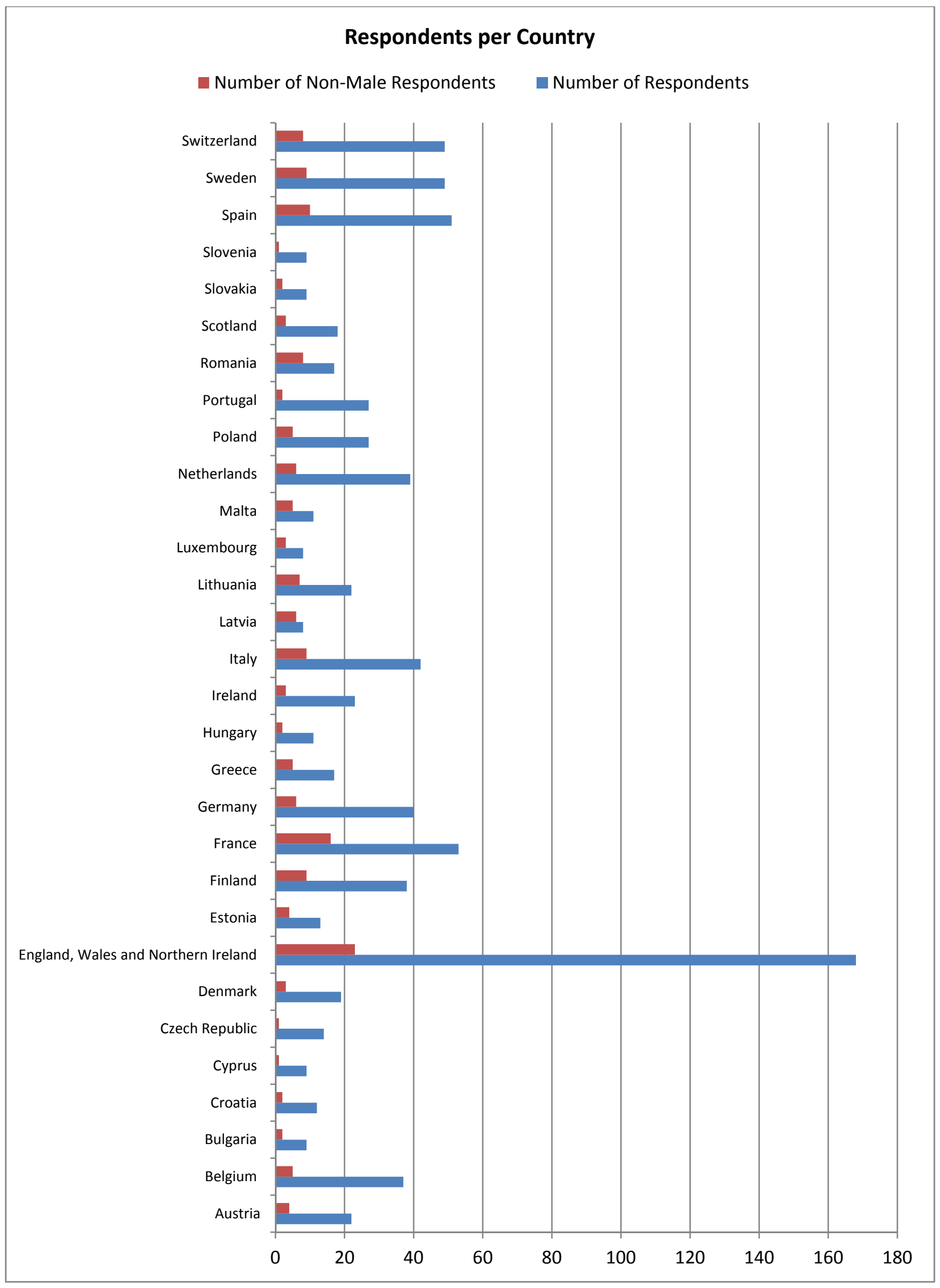




\section{Have You Served as an Arbitrator in the Past Five Years?}
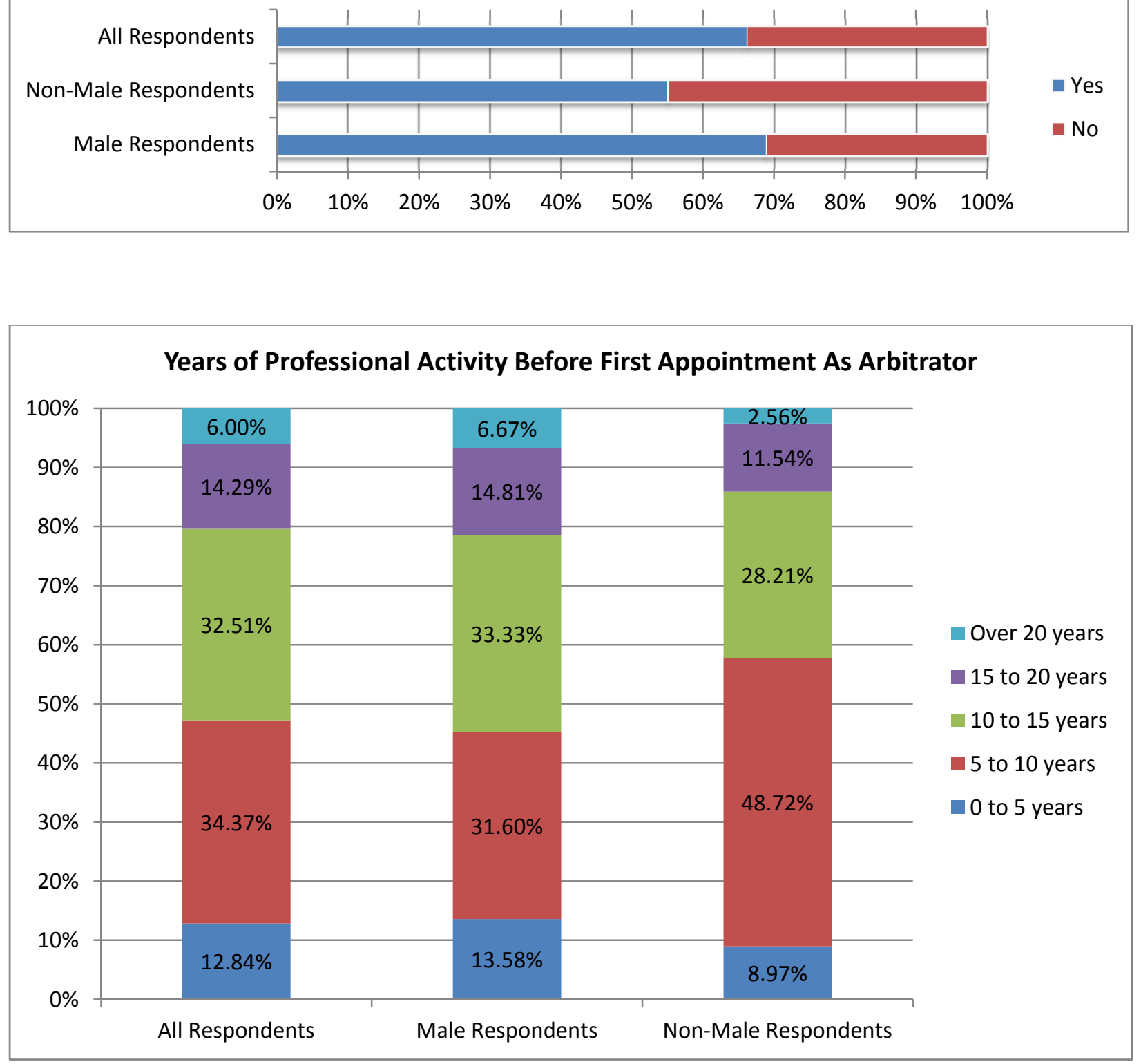


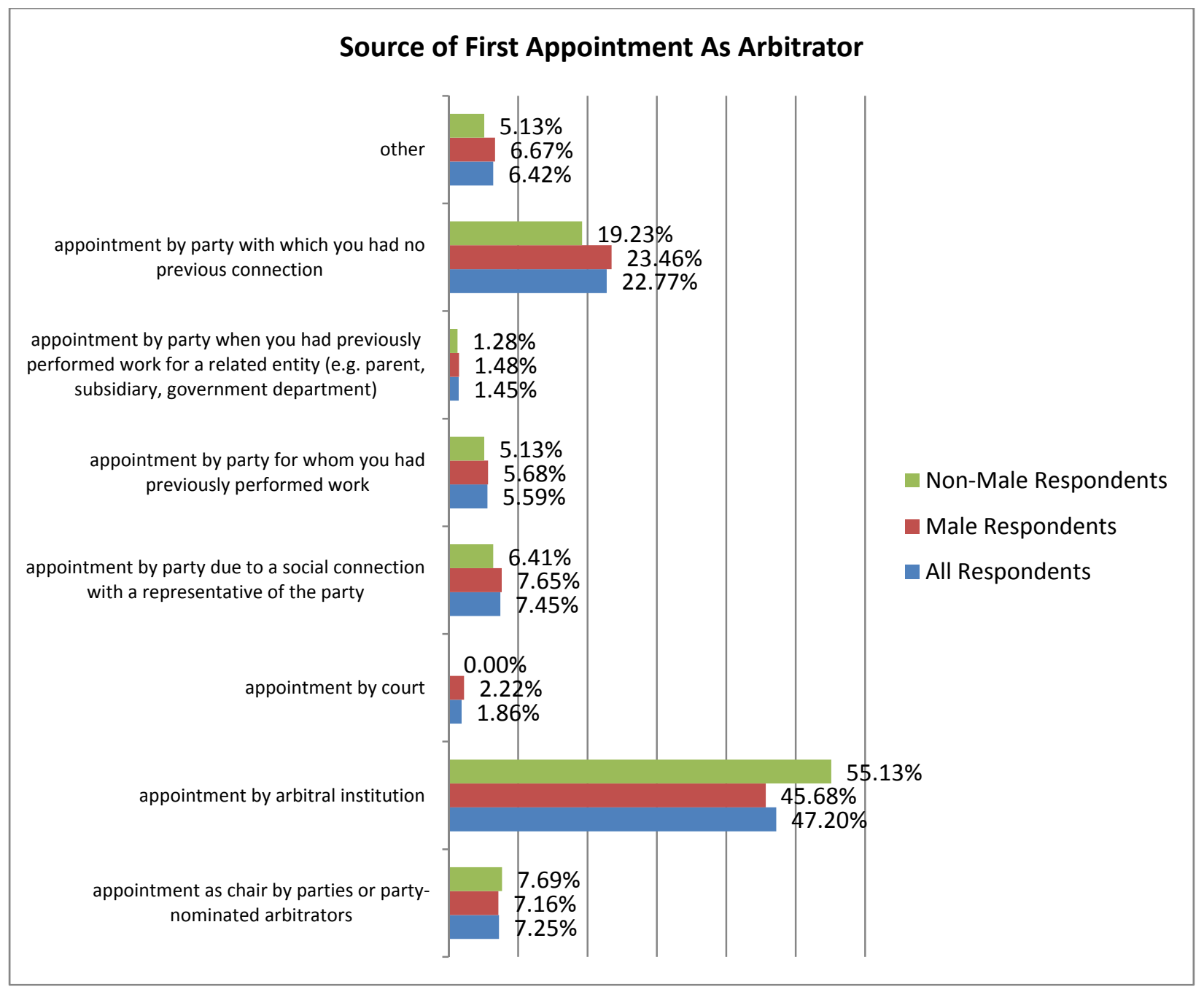









\section{Sources of Appointments as Arbitrator Over the Past Five Years - Non- Male Respondents}

By parties whose counsel had previously represented a party that appointed you as arbitrator

By an arbitral institution

By a party with which your connection was a social connection with a representative of that party

By a party with which you had no previous contact

By a party that had previously participated in an arbitration in which you were appointed by the opposing party

By a party that had previously appointed you as an arbitrator

By a court

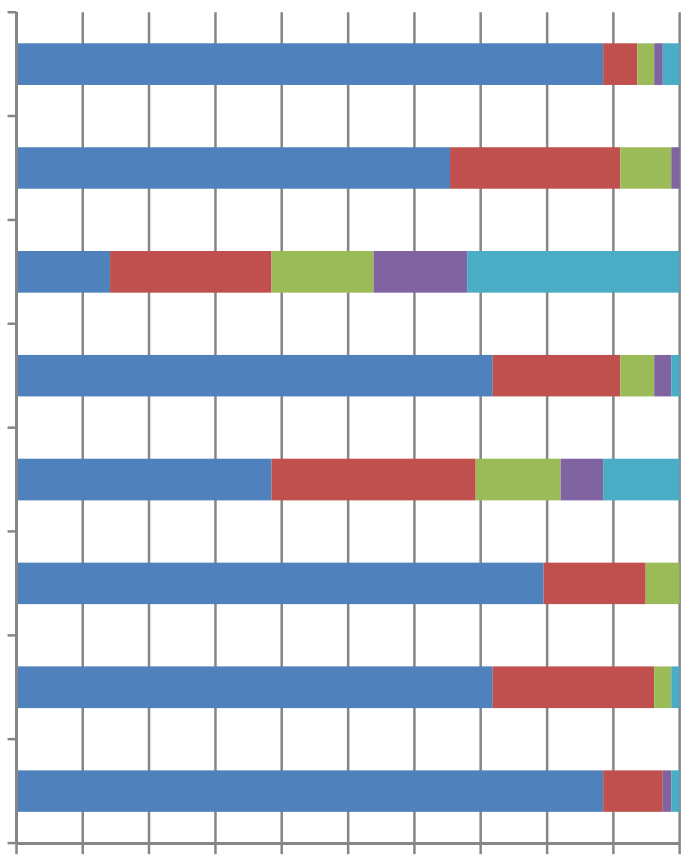

0

- $1-25 \%$

$26-50 \%$

- 51-75\%

$76-100 \%$

0\% 10\% 20\% 30\% 40\% 50\% 60\% 70\% 80\% 90\% $100 \%$ 


\section{Sources of Appointments as Arbitrator Over the Past Five Years - Male Respondents}

party that appointed you as arbitrator

By an arbitral institution

By a party with which your connection was a social connection with a representative of that party

By a party with which you had no previous contact

By a party that had previously participated in an arbitration in which you were appointed by the opposing party

By a party that had previously appointed you as an arbitrator

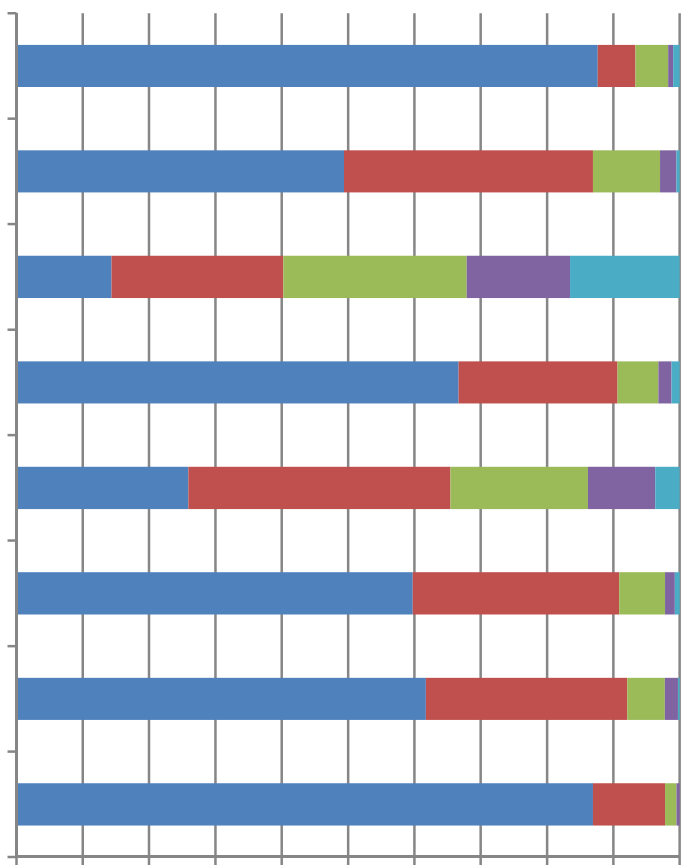

By a court

0\% 10\% 20\% 30\% 40\% 50\% 60\% 70\% 80\% 90\%100\% 


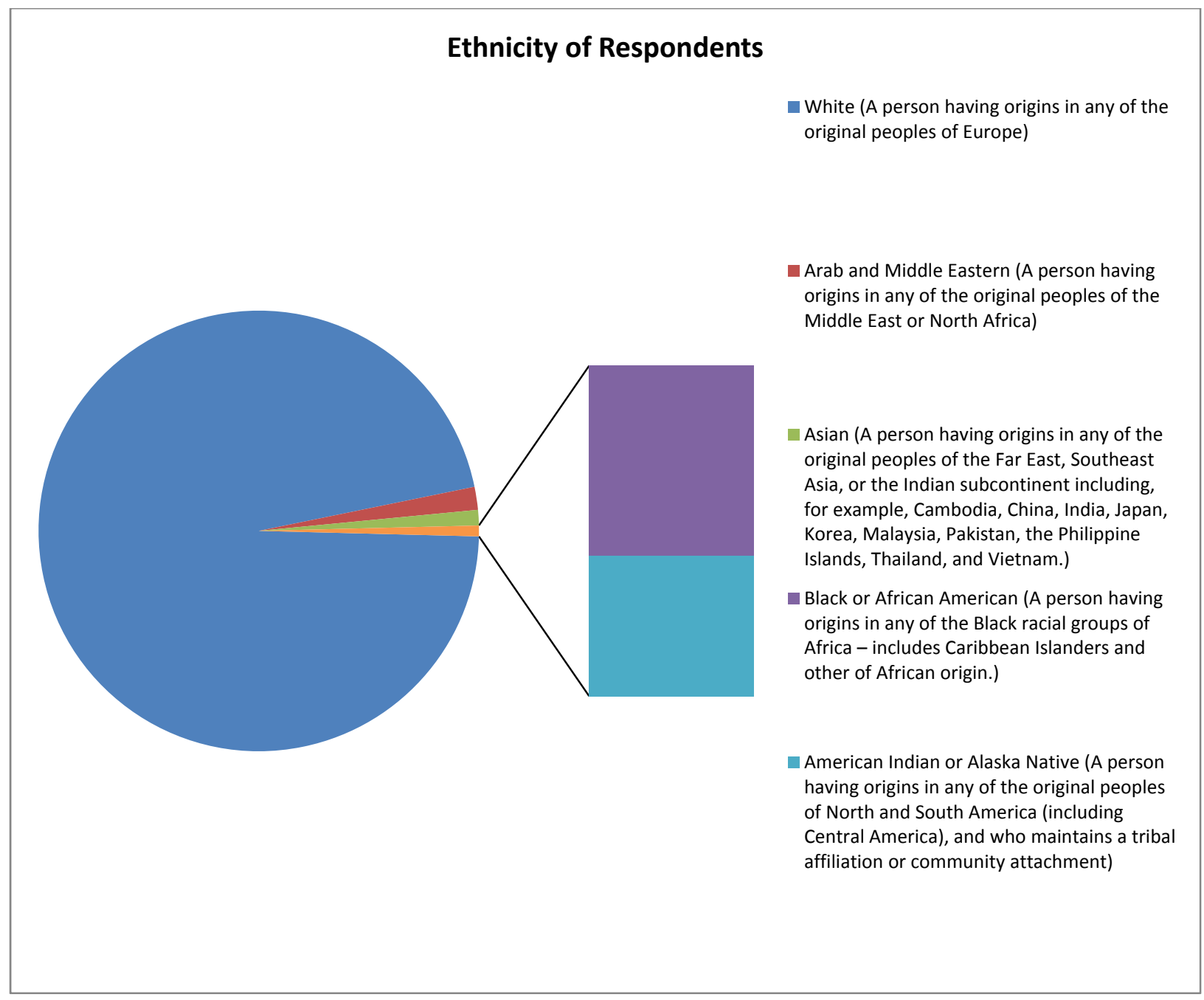




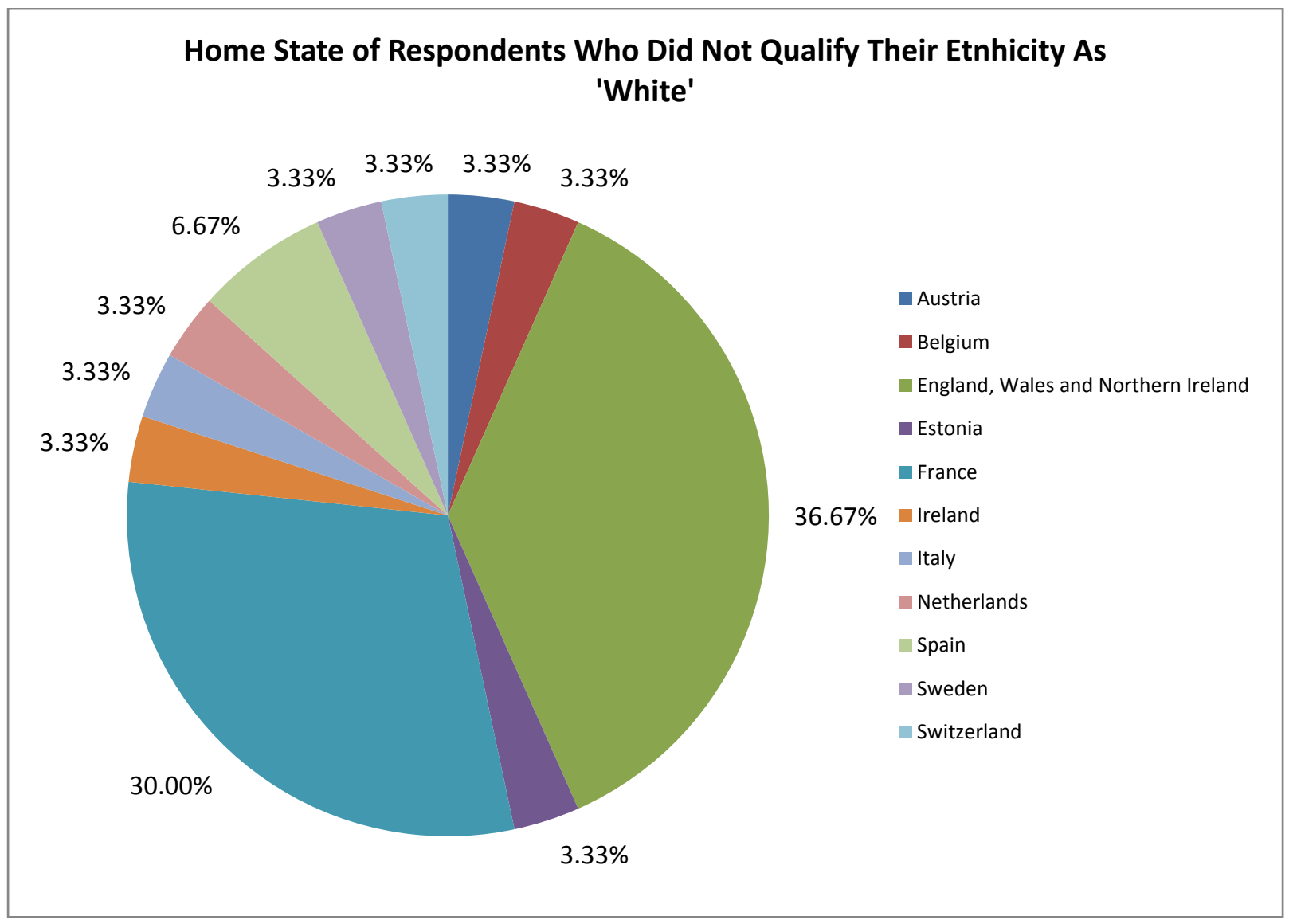

